\section{Effectiveness of cyclosporine and mycophenolate mofetil in a child with refractory evans syndrome}

\author{
Piero Farruggia, ${ }^{1}$ Alessandra Macaluso, ${ }^{2}$ \\ Serena Tropia,1 Selene Genova,2 \\ Olivia Paolicchi, 3 Floriana Di Marco,1 \\ Paolo D'Angelo1 \\ 1Pediatric Hematology and Oncology \\ Unit, G. Di Cristina Children's Hospital, \\ Palermo; 2Department of Pediatrics, \\ G. Di Cristina Children's Hospital, \\ University of Palermo, Palermo; \\ 3Department of Pediatric Hematology \\ and Oncology, A.O.U. Meyer Children \\ Hospital, Florence, Italy
}

\section{Abstract}

Evans Syndrome is a rare autoimmune disease consisting of hemolytic anemia, thrombocytopenia and/or neutropenia. It may be associated with other autoimmune or lymphoproliferative diseases. Its course can be extremely serious and, rarely, even life-threatening; thus it represents a excellent treatment challenge for the pediatric hematologist. First line treatment consists of steroids and/or immunoglobulin; further therapy with rituximab, vincristine, cyclophosphamide and other immunosuppressive drugs can be considered in unresponsive patients. We describe a baby with refractory Evans Syndrome that was cured by prolonged administration of mycophenolate mofetil and remained disease-free for 4 years after the discontinuation of treatment.

\section{Introduction}

Evans Syndrome (ES) is an autoimmune disorder characterized by thrombocytopenia and/or neutropenia associated with hemolytic anemia (AHA). ${ }^{1-3}$ It is a potentially life-threatening condition that may be associated with other underlying autoimmune or lymph-proliferative disorders. ${ }^{4}$ Standard treatment consists of transfusions, corticosteroids and immunoglobulins (IVIG); second-line treatment in ES evolved over the last decade, and includes at present anti-CD20 rituximab, vincristine, alkalizing agents, mycophenolate mofetil (MMF) or cyclosporine (CyA). - $-6,8-14^{-14}$ Long-term remissions induced by splenectomy are less frequent than in uncomplicated immune thrombocytopenia purpura (ITP). This menu challenges the hematologist to pick the best option suitable for each specific patient even though, above all in younger children, the course of ES can be extremely serious. ${ }^{4}$ Sometimes it can be difficult to choose the best treatment.

\section{Case Report}

A.G., female, 18 months, was initially diagnosed with ITP, only transiently responsive to IVIG $(1 \mathrm{~g} / \mathrm{kg})$ and refractory to oral prednisone ( $2 \mathrm{mg} / \mathrm{kg} /$ day for two weeks). After one month, soon after prednisone stop, she developed palor, petecchiae, skin and conjunctive jaundice and mild hepatomegaly (liver margin palpable at $3 \mathrm{~cm}$ below the costal margin).

Blood count showed: Hb $5.3 \mathrm{~g} / \mathrm{dL}, \mathrm{RBC}$ $1,730,000 / \mu \mathrm{L}, \mathrm{MCV} 93.6 \mathrm{fl}, \mathrm{WBC} 12,970 / \mu \mathrm{L}$, PLTS $4,000 / \mu \mathrm{L}$, reticulocytes $22.5 \%$; direct antiglobulin test (DAT) and indirect antiglobulin test extremely positive (with IgG specificity), LDH 525 u/L, AST 48 u/L, ALT 14 u/L, bilirubin direct/total $0.68 / 4.1 \mathrm{mg} / \mathrm{dL}$. On the basis of the finding of AHA, the diagnosis was changed from ITP into ES. Screening for autoantibodies (ANA, ENA, anti-DNA, AMA, ASMA) was completely negative.

The baby was refractory to several lines of treatment: IVIG (1 g/kg), oral prednisone ( $2 \mathrm{mg} / \mathrm{kg} /$ day for two weeks), intravenous methylprednisolone $(25 \mathrm{mg} / \mathrm{kg} /$ day for three consecutive days), rituximab i.v. (four weekly doses at $375 \mathrm{mg} / \mathrm{sqm})$, vincristine i.v. (1.5 $\mathrm{mg} / \mathrm{sqm})$, cyclophosphamide i.v. (600 mg/sqm), thus remaining completely dependent on both erythrocyte and platelet transfusions for about four months. Finally oral CyA (5 mg/kg/day) was started; this therapy made the baby immediately transfusion-free with $\mathrm{Hb}$ ranging between 7 and $12 \mathrm{~g} / \mathrm{dL}$, positive DAT and reticulocytes count of more than $15 \%$. Interestingly, thrombocytopenia persisted $(<5,000 / \mu \mathrm{L})$ and became symptomatic with frequent bleeding into the skin and mucous membranes.

After six months, therapy with MMF was started $(50 \mathrm{mg} / \mathrm{kg} / \mathrm{die}$ ) and CyA was slowly tapered over 2 months. A stable increase of hemoglobin (>12 $\mathrm{g} / \mathrm{dL})$ and platelets $(>20,000 / \mu \mathrm{l})$ was observed after 2 months (soon after the discontinuation of CyA), and 4 months of MMF therapy, respectively. On day 45 of MMF therapy, the DAT became almost negative and reticulocyte count dropped to $<2 \%$. A normal platelet count $(>150.000 / \mu \mathrm{L})$ was documented since 8 months of MMF therapy. No adverse drug-related effect was noted. After 1 year, MMF was slowly tapered and then stopped in nine months (about 22 months after the beginning of treatment). DAT remained negative since 12 months after discontinuation of MMF. Figures 1 and 2 show hemoglobin and platelets levels respectively
Correspondence: Piero Farruggia, Pediatric Hematology and Oncology Unit, G. Di Cristina Children's Hospital, via Benedettini 1, 90134 Palermo, Italy.

Tel. +39.91.6666034 - Fax. +39.91.6664127

E-mail: pfarruggia@libero.it

Key words: evans syndrome, cyclosporine, mycophenolate mofetil, treatment, outcome.

Acknowledgements: the authors are grateful to Prof. Frank Adamo for language support, and the parents' Association "A.S.L.T.I.-Liberi di crescere" Onlus for the financial support.

Contributions: PF, patient clinical management, manuscript conception, design and editing, literature review, manuscript final approval; AM, clinical and laboratory reports collection, manuscript conception and design; figures preparation; ST, patient clinical management, SG, clinical and laboratory reports collection, figures preparation; OP, literature review; FDM, clinical and laboratory reports collection, manuscript editing; PD, patient clinical management, manuscript editing and literature review, manuscript final approval.

Conflict of interest: the authors report no conflicts of interest.

Received for publication: 24 March 2011

Accepted for publication: 2 May 2011.

This work is licensed under a Creative Commons Attribution 3.0 License (by-nc 3.0).

(C) Copyright P. Farruggia et al., 2011

Licensee PAGEPress, Italy

Pediatric Reports 2011; 3:e15

doi:10.4081/pr.2011.e15

during the whole period of observation. Now the girl is well, in complete remission 6 years after diagnosis and about 48 months after completion of therapy.

\section{Discussion}

Treatment of ES is often troublesome, especially in cases with reticulocytopenia, resulting from IgM autoagglutinins, or in infants, when the course can be extremely serious or fatal. Despite novel treatment modalities, standard therapy remains to be established. Steroid and IVIG are the traditional first-line therapies, $1,4,5$ but a B-cell targeted therapy with the use of a mouse/human chimeric IgG1 anti-CD20 monoclonal antibody, rituximab, has gained widespread acceptance in cases refractory to more conventional treatment; suppression of autoreactive B cells may explain the response. ${ }^{6}$

However, many issues still remain, including optimal dose, long-term effectiveness and side 
effects. Recently the association of Progressive Multifocal Leukoencephalopathy (PML) with rituximab (although the absolute risk of developing PML is low), has raised some doubts about the use of anti-CD20 in non-oncological diseases. ${ }^{7}$ Our patient with ES was refractory to steroids, IVIG and rituximab. Due to the age and the limited chance of cure, we did not advise splenectomy. Chemotherapeutic agents like vincristine or cyclophosphamide, sporadically used with equivocal results, also proved ineffective in our patient. 8,9

Sporadic reports suggested a potential effect of MMF and CyA, two immunosuppressive drugs. ${ }^{10-14}$ We decided to start with CyA, relatively more often reported, at a dose of 5 $\mathrm{mg} / \mathrm{kg} /$ day. The effect on red blood cell transfusion dependency was immediate: after the start of CyA the child was transfused only one time. Unfortunately there was no effect on platelet count, and the child's quality of life was hampered by persistent skin and mucosal bleeding. Thus, we decided to add MMF to CyA. The combined therapy rapidly demonstrated a stronger activity than previous monotherapy with CyA. Hemoglobin increased to $>12 \mathrm{~g} / \mathrm{dL}$ and reticulocytes dropped to $<2 \%$. Cyclosporine was stopped after two months of combined use with MMF and no sign of AHA relapse was noted. The clinical signs of thrombocytopenia started to decrease about three months after beginning the drug, but a normal count of platelets was achieved only after 8 months of MMF therapy, so we are not able to confirm that the resolution is surely due to the effect of the drug.

Cyclosporine suppresses the immune response by inhibiting the action of calcineurin, which results in a failure to activate the genes required for B-cell help and for T-cell proliferation, whereas MMF, reducing guanine nucleotide pools in lymphocytes, inhibits proliferative responses of T- and B-lymphocytes to both mitogenic and allospecific stimulation. Due to lack of such reports, we cannot assess if in our case some synergy between the immune-suppressors may have occurred.

In conclusion, we suggest that based on our experience in this case, the combination of MMF and CyA could be considered after more conventional drugs (IVIG, steroid, rituximab) or other second choice drugs (vincristine, cyclophosphamide) have failed. For patients failing after several lines of treatment, and remaining in life-threatening condition, allogeneic hematopoietic stem cell transplantation (HSCT) should be considered, especially if an HLA-identical donor is available in the family. 15

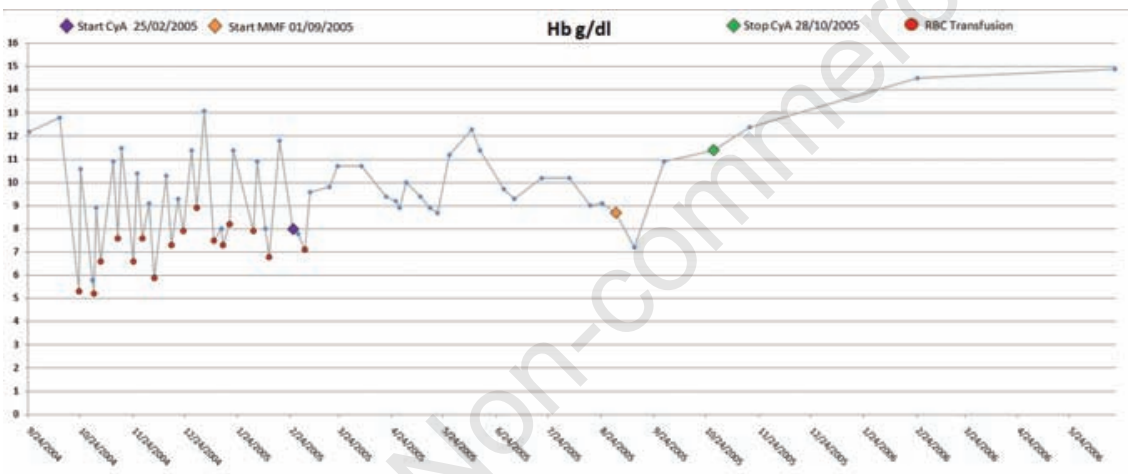

Figure 1. Haemoglobin trend during the observation period.

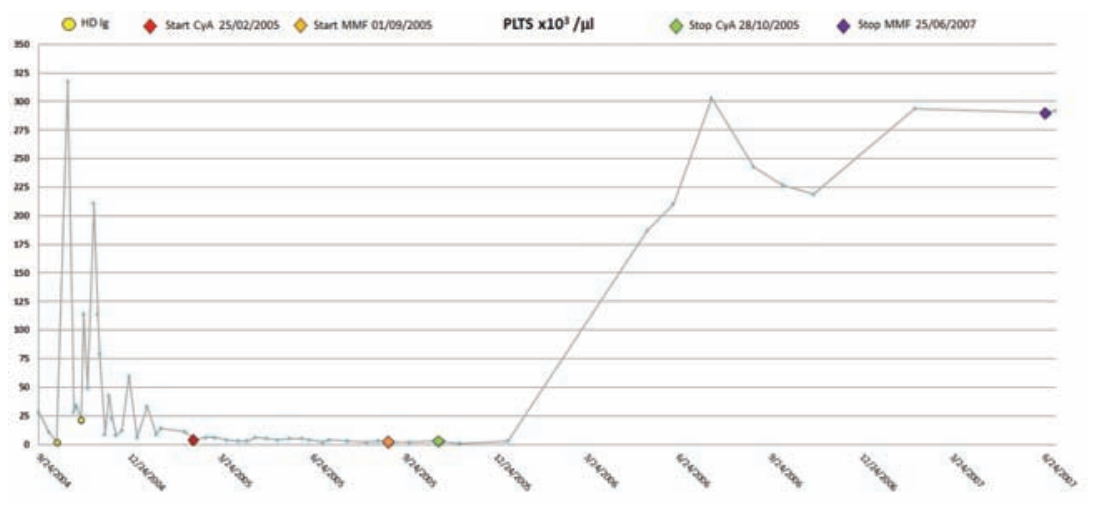

Figure 2. Platelets count during the observation period.

\section{References}

1. Petz LD, Garratty G. Immune hemolytic anemias. New York: Churchill Livingstone, 2004.

2. Savasan S, Warrier I, Ravindranath Y. The spectrum of Evans' syndrome. Arch Dis Child 1997;77:245-8.

3. Blouin P, Auvrignon A, Pagnier A, et al. Evans' syndrome: a retrospective study from the ship (French Society of Pediatric Hematology and Immunology) (36 cases). Arch Pediatr 2005;12:1600-7.

4. Friedmann AM, King KE, Shirey RS, et al. Fatal autoimmune hemolytic anemia in a child due to warm-reactive immunoglobulin M antibody. J Pediatr Hematol Oncol 1998;20: 502-5.

5. Nuss R, Wang W. Intravenous gamma globulin for thrombocytopenia in children with Evans syndrome. Am J Pediatr Hematol Oncol 1987;9:164-7.

6. Zecca M, Nobili B, Ramenghi U, et al. Rituximab for the treatment of refractory autoimmune hemolytic anemia in children. Blood 2003;101:3857-61.

7. Carson KR, Evens AM, Richey EA, et al. Progressive multifocal leukoencephalopathy after rituximab therapy in HIV-negative patients: a report of 57 cases from the Research on Adverse Drug Events and Reports project. Blood 2009;113:4834-40.

8. Scaradavou A, Bussel J. Evans syndrome. Results of a pilot study utilizing a multiagent treatment protocol. J Pediatr Hematol Oncol 1995;17:290-5.

9. Gombakis N, Trahana M, Athanassiou M, Kanakoudi-Tsakalidou F. Evans syndrome: successful management with multi-agent treatment including intermediate-dose intravenous cyclophosphamide. J Pediatr Hematol Oncol 1999;21:248-9.

10. Zimmer-Molsberger B, Knauf W, Thiel E. Mycophenolate mofetil for severe autoimmune haemolytic anemia. Lancet 1997;350:1003-4.

11. Kotb R, Pinganaud C, Trichet C, et al. Efficacy of mycophenolate mofetil in adult refractory auto-immune cytopenias: a single center preliminary study. Eur J Haematol 2005;75:60-4.

12. Hershko C, Sonnenblick M, Ashkenazi J. Control of steroid-resistant autoimmune haemolytic anaemia by cyclosporine. $\mathrm{Br} \mathrm{J}$ Haematol 1990;76:436-7.

13. Uçar B, Akgün N, Aydo $\square$ du SD, et al. Treatment of refractory Evans' syndrome with cyclosporine and prednisone. Pediatr Int 1999; 41:104-7.

14. Guirat Dhouib N, Mellouli F, Kouki R, Bejaoui M. Successful treatment of Mycophenolate Mofetil in a child with refractory Evans Syndrome. J Pediatr Hematol Oncol 2010;32:e2 44.

15. Caselli D, Farruggia P, Trizzino A, et al. Split chimerism may be enough to cure Evans syndrome. Bone Marrow Transplant 2006;38:311. 